\title{
Should we restrict erythrocyte transfusion in early goal directed protocols?
}

\author{
Patrick Meybohm ${ }^{1 *}$, Aryeh Shander ${ }^{2}$ and Kai Zacharowski ${ }^{1}$
}

\begin{abstract}
Background: Early goal-directed therapy has been endorsed in the guidelines of the Surviving Sepsis Campaign as a key strategy among patients presenting with severe sepsis or septic shock. But more importantly, early goal-directed therapy also became standard care for non-septic critically ill patients and was adopted for high-risk surgical patients.

Discussion: Importantly, transfusion of red blood cells is a central part of many protocols of early goal-directed therapy to indicate the need for use of inotropes and red blood cells, as both central venous saturation and hematocrit are used as transfusion triggers. However, burgeoning data has strongly linked transfusion with worse clinical outcomes. If correct, could these early goal-directed therapy ,bundles' have better outcome if a restrictive transfusion practice is adopted?

Summary: Early goal-directed therapy has evolved as standard care for most of critically ill patients, and many protocols contain transfusion of red blood cells targeting high hemoglobin level as a key element. As red blood cell transfusions are associated with increased morbidity and mortality, transfusion thresholds need to be more individualized.
\end{abstract}

Keywords: Allogeneic blood transfusion, Protocol directed therapy

\section{Background}

In a single-center study published in 2001 involving patients presenting with severe sepsis and septic shock, mortality was markedly lower among those who were treated according to a 6-hour protocol of early goal-directed therapy (EGDT) than among those receiving usual care [1]. The EGDT protocol included indications for central venous pressure and mean arterial pressure $(<65 \mathrm{~mm} \mathrm{Hg})$ to guide both fluid and vasopressor administration. Additionally, both central venous saturation $(<70 \%)$ and hematocrit $(<30 \%)$ were included to indicate the need for use of inotropes and red blood cell (RBC) transfusion, respectively.

Importantly, burgeoning data has strongly linked transfusion with worse clinical outcomes. If correct, could these EGDT ,bundles' have better outcome if a restrictive transfusion practice is adopted?

\footnotetext{
* Correspondence: patrick.meybohm@kgu.de

'Department of Anaesthesiology, Intensive Care Medicine and Pain Therapy, University Hospital Frankfurt, Theodor-Stern-Kai 7, 60590 Frankfurt am Main, Germany

Full list of author information is available at the end of the article
}

\section{Discussion}

Following these auspicious results [1] EGDT has been endorsed in the guidelines of the Surviving Sepsis Campaign as a key strategy among patients presenting with severe sepsis or septic shock. But more importantly, EGDT also became standard care for non-septic critically ill patients and more recently, EGDT was adopted for high-risk surgical patients [2]. Thus, protocols were implemented at hospitals around the world incorporating all elements of the care bundle, but the impact of the different elements of an EGDT protocol has yet to be individually investigated. Based on current knowledge, it may be conceivable that individual elements may even be harmful (e.g. RBC transfusion and central venous pressure), and thereby reducing the potential of more beneficial effects.

In this respect, we would like to caution the reader:

In previous EGDT protocols transfusion of RBC targeting hemoglobin $>8 \mathrm{~g} / \mathrm{dL}$ or hematocrit level $>30 \%$ is a key element to increase central venous oxygen saturation (Table 1). Importantly, evidence for augmentation of oxygen delivery and thereby increase of central venous oxygen saturation above $70 \%$ by $R B C$ transfusion is 
Table 1 Overview of early-goal directed protocols and high transfusion triggers (selection)

\begin{tabular}{|c|c|c|}
\hline Study & Field of interest & RBC transfusion trigger \\
\hline Rivers et al. [1] & Severe sepsis and septic shock & $\mathrm{Hct}<30 \%$, if $\mathrm{ScvO}_{2}<70 \%$ \\
\hline Lobo et al. [10] & Major non-cardiac surgery & $\mathrm{Hct}<30 \%$, if $\mathrm{PAOP}<16 \mathrm{~mm} \mathrm{Hg}$ \\
\hline Donati et al. [11] & Major abdominal surgery & $\mathrm{Hb}<10 \mathrm{~g} / \mathrm{dl}$, if CVP $<10 \mathrm{~mm} \mathrm{Hg}$ \\
\hline Smetkin et al. [12] & Cardiac surgery & $\mathrm{Hb}<8 \mathrm{~g} / \mathrm{dl}$, if $\mathrm{ScvO}_{2}<60 \%$ \\
\hline ProMISe Investigators [13] & Severe sepsis and septic shock & $\mathrm{Hb}<10 \mathrm{~g} / \mathrm{dl}$, if $\mathrm{ScvO}_{2}<70 \%$ \\
\hline ProCESS Investigators [4] & Septic shock & $\mathrm{Hct}<30 \%$, if $\mathrm{ScvO}_{2}<70 \%$ \\
\hline ARISE Investigators [5] & Septic shock & $\mathrm{Hct}<30 \%$, if $\mathrm{ScvO}_{2}<70 \%$ \\
\hline
\end{tabular}

$\mathrm{Hct}$ indicates hematocrit; $\mathrm{Hb}$, hemoglobin; $\mathrm{ScvO}_{2}$, central venous oxygen saturation; CVP, central venous pressure; PAOP, pulmonary artery occlusion pressure.

poor. In contrast, a rational use of RBC concentrates is mandatory, as RBC transfusions are associated with increased morbidity and mortality [3].

In the recent ProCESS trial [4] 1,341 patients with septic shock were randomly assigned to one of three groups for 6 hours of resuscitation: protocol-based EGDT including RBC transfusion if hematocrit $<30 \%$ and central venous saturation $<70 \%$; protocol-based standard therapy or usual care. The primary end point was 60-day in-hospital mortality. Not surprisingly, patients in the EGDT group compared to usual care received significantly more vasopressors $(54.9 \%$ vs. $44.1 \%, \mathrm{P}=0.003)$, more dobutamine $(8.0 \%$ vs. $0.9 \%$; $\mathrm{P}<0.001)$, and more $\mathrm{RBC}$ transfusion $(14.4 \%$ vs. $7.5 \%$; $\mathrm{P}=0.001)$ without any clinical benefit but used more resources.

In the more recent ARISE trial [5] 1,600 patients with early septic shock were randomly assigned to receive either EGDT or usual care. The primary outcome was all-cause mortality within 90 days after randomization. Again, patients in the EGDT group were more likely to receive vasopressor infusions $(66.6 \%$ vs. $57.8 \%$; $\mathrm{p}<0.001)$, dobutamine $(15.4 \%$ vs. $2.6 \%$; $\mathrm{p}<0.001)$, and RBC transfusion $(13.6 \%$ vs. $7.0 \% ; \mathrm{P}<0.001)$ again with very similar outcomes as ProCESS.

Both studies confirmed the most important elements in management of sepsis: early administration of antibiotics and early adequate volume resuscitation using clinical parameters ascribed by the protocol. Of note two of the areas questioned here, the indication for dobutamine and transfusion "triggers" of hematocrit $<30 \%$ must be reassessed in light of existing evidence.

$\mathrm{RBC}$ transfusions are frequently given to patients with septic shock. Few of these transfusions are given to patients who are bleeding and most to non-bleeding patients. However, the use of a high hemoglobin threshold for transfusion as part of an EGDT protocol should be questioned. In this respect, Holst et al. [6] compared two different transfusion strategies and randomized 1,005 patients with septic shock to receive one unit RBC when the hemoglobin level was $\leq 7 \mathrm{~g} / \mathrm{dl}$ (lower threshold) or when the level was $\leq 9 \mathrm{~g} / \mathrm{dl}$ (higher threshold) during the ICU stay. Primary endpoint was mortality at 90 days that was similar between both groups. However, the lowerthreshold group received a median of 1 unit of blood (interquartile range, 0 to 3 ) and the higher-threshold group received a median of 4 units (interquartile range, 2 to 7 ). These authors concluded that RBC transfusion at a hemoglobin threshold of $7 \mathrm{~g} / \mathrm{dl}$ is safe in septic patients, and a higher threshold was not beneficial and resulted in a 10-20 times higher transfusion adverse events.

In high-risk cardiac surgical patients, Murphy et al. [7] recently randomly assigned 2,007 patients post cardiac surgery (they were either revasculerized or replaced defective valves) to a restrictive transfusion threshold (hemoglobin level $<7.5 \mathrm{~g} / \mathrm{dl}$ ) or a liberal transfusion threshold (hemoglobin level $<9 \mathrm{~g} / \mathrm{dl}$ ) group. The primary outcome was a serious infection (sepsis or wound infection) or an ischemic event (permanent stroke, myocardial infarction, infarction of the gut, or acute kidney injury) within 3 months after surgery. Transfusion rates were $53.4 \%$ (higher than many liberal transfusion hospitals) and $92.2 \%$ in the two groups, respectively. The restrictive transfusion threshold was not inferior to the liberal threshold with respect to morbidity or 30 day mortality. Mortality at 90 days was statistically higher in the restrictive group with 16 more deaths than in the liberal-threshold group. These finding are perplexing since the causes of death were not related to anemia and no plausible mechanism was offered by the authors. In this respect, this study provides non-inferiority data on restrictive transfusion and should not result in change of practice until these findings are either corroborated or refuted. It is also unclear whether the liberal transfused group were benefiting from the 'volume therapy' which the restrictive group has not received.

In-line with this discussion, two US health care organizations (American Medical Association Physician Consortium for Performance Improvement ${ }^{\circ}$ and The Joint Commission) have previously recommended strategies to minimize overuse in healthcare, naming blood products as one of the top five targets. In addition, the Choosing Wisely campaign launched by the American Board of Internal Medicine Foundation both in US and now Canada, repeat the same message [8]. The World Health Organization has 
adopted resolution 63.12, also adopted by the United States Department of Health and Human Services, recommending all member states to implement a patient blood management (PBM) program employing multiple strategies to minimize unnecessary exposure to blood products as a new standard of care. In detail, PBM is a proactive evidence based approach to identify, diagnose and treat anemia before a transfusion threshold is met. Optimization of hemostasis and minimization of blood loss are additional core principles of PBM to reduce costs and to improve patient outcome [9].

\section{Summary}

EGDT has evolved as standard care for most of critically ill patients, and many EGDT protocols contain transfusion of $\mathrm{RBC}$ targeting hemoglobin $>8 \mathrm{~g} / \mathrm{dL}$ or hematocrit level $>30 \%$ as a key element to increase central venous oxygen saturation. In contrast, $\mathrm{RBC}$ transfusions are associated with increased morbidity and mortality, and therefore, a PBM program to minimize unnecessary exposure to blood products could be adopted within EGDT protocols. Additionally, transfusion thresholds for $\mathrm{RBC}$ transfusion need to be more individualized.

\section{Abbreviations}

EGDT: Early goal directed therapy; PBM: Patient blood management; RBC: Red blood cell.

\section{Competing interests}

PM and KZ are involved in a multicenter epidemiologic project focusing on implementation of patient blood management.

\section{Authors' contributions}

PM, AS and KZ wrote the manuscript. All authors read and approved the final manuscript.

\section{Author details \\ ${ }^{1}$ Department of Anaesthesiology, Intensive Care Medicine and Pain Therapy, University Hospital Frankfurt, Theodor-Stern-Kai 7, 60590 Frankfurt am Main, Germany. ${ }^{2}$ Department of Anesthesiology and Critical Care and Hyperbaric Medicine, Englewood Hospital and Medical Center, Anesthesiology and Critical Care and Hyperbaric Medicine, Englewood, NJ, USA.}

Received: 23 February 2015 Accepted: 29 April 2015

Published online: 09 May 2015

\section{References}

1. Rivers E, Nguyen B, Havstad S, Ressler J, Muzzin A, Knoblich B, et al. Early goal-directed therapy in the treatment of severe sepsis and septic shock. N Engl J Med. 2001;345:1368-77.

2. Aya HD, Cecconi M, Hamilton M, Rhodes A. Goal-directed therapy in cardiac surgery: a systematic review and meta-analysis. Br J Anaesth. 2013:110:510-7

3. Rohde JM, Dimcheff DE, Blumberg N, Saint S, Langa KM, Kuhn L, et al. Health care-associated infection after red blood cell transfusion: a systematic review and meta-analysis. JAMA. 2014;311:1317-26.

4. Investigators PC, Yealy DM, Kellum JA, Huang DT, Barnato AE, Weissfeld LA et al. A randomized trial of protocol-based care for early septic shock. $N$ Engl J Med. 2014:370:1683-93.

5. Investigators A, Group ACT, Peake SL, Delaney A, Bailey M, Bellomo R, et al. Goal-directed resuscitation for patients with early septic shock. N Engl J Med. 2014;371:1496-506.
6. Holst LB, Haase N, Wetterslev J, Wernerman J, Guttormsen AB, Karlsson S, et al. Lower versus higher hemoglobin threshold for transfusion in septic shock. N Engl J Med. 2014;371:1381-91.

7. Murphy GJ, Pike K, Rogers CA, Wordsworth S, Stokes EA, Angelini GD, et al, Liberal or restrictive transfusion after cardiac surgery. $N$ Engl J Med. 2015:372:997-1008.

8. Choosing wisely [http://www.choosingwisely.org/doctor-patient-lists/]

9. Frank SM, Wick EC, Dezern AE, Ness PM, Wasey JO, Pippa AC, et al. Risk-adjusted clinical outcomes in patients enrolled in a bloodless program. Transfusion. 2014;54:2668-77.

10. Lobo SM, Lobo FR, Polachini CA, Patini DS, Yamamoto AE, de Oliveira NE, et al. Prospective, randomized trial comparing fluids and dobutamine optimization of oxygen delivery in high-risk surgical patients [ISRCTN42445141]. Crit Care. 2006;10:R72.

11. Donati A, Loggi S, Preiser JC, Orsetti G, Munch C, Gabbanelli V, et al. Goal-directed intraoperative therapy reduces morbidity and length of hospital stay in high-risk surgical patients. Chest. 2007:132:1817-24.

12. Smetkin AA, Kirov MY, Kuzkov W, Lenkin Al, Eremeev AV, Slastilin VY, et al. Single transpulmonary thermodilution and continuous monitoring of central venous oxygen saturation during off-pump coronary surgery. Acta Anaesthesiol Scand. 2009:53:505-14.

13. Mouncey PR, Osborn TM, Power GS, Harrison DA, Sadique MZ, Grieve RD, et al. Trial of Early, Goal-Directed Resuscitation for Septic Shock. N Engl J Med. 2015;372(14):1301-11.

\section{Submit your next manuscript to BioMed Central and take full advantage of:}

- Convenient online submission

- Thorough peer review

- No space constraints or color figure charges

- Immediate publication on acceptance

- Inclusion in PubMed, CAS, Scopus and Google Scholar

- Research which is freely available for redistribution 